REVISION

\title{
LAS DISCUSIONES EDUCACIONALES EN EL CHILE DEL CENTENARIO
}

\section{The Discussions about Education in the Centennial Chile}

\author{
As discussões sobre Educação no Chile do Centenário
}

\author{
Andrés Donoso Romo, Sebastián Donoso Díaz*1 \\ *CONICYT-CIE-05, correo sdonoso@utalca.cl
}

Debe existir una congruencia de fines entre Sociedad y Escuela, para que la acción orientadora de ambas combine sus fuerzas y no arroje al individuo al escepticismo y a la colectividad a la desintegración. (Labarca, Amanda. 1943: 25)

\section{RESUMEN}

El artículo tiene por finalidad relevar las principales discusiones educacionales realizadas en el período del Centenario en Chile (1880-1930), dando cuenta del rol que se le asigna a la educación según los actores sociales más relevantes, de los principales problemas que se les demanda solucionar y de las dificultades que enfrentan para realizar esta tarea, como igualmente, de los contenidos que asume y de la significación que adquiere la educación en el desarrollo del país. Finalmente se analizan en forma breve los aspectos señalados con algunos de los temas clave del debate del Bicentenario en el cual nos encontramos inmersos en la actualidad.

Palabras clave: política educacional chilena, educación pública, problemas educacionales del siglo XX.

\begin{abstract}
The article aims at revealing the main discussions about education during the period of the centennial in Chile (1880-1930), outlining the role ascribed to the education, the main problems that had to be solved, and the difficulties the most relevant social actors came across to accomplish this task. In addition, the article describes the contents assumed by the education and the significance it has acquired in the country's development. Finally, the aspects mentioned are briefly analyzed in relation to some of the key topics of the bicentennial debate in which we are immersed nowadays.
\end{abstract}

Key words: chilean educational policy, public education, educational problems of the twentieth century.

\section{RESUMO}

$\mathrm{O}$ artigo apresenta às principais discussões educacionais que aconteceram no período do centenário no Chile (1880-1930), mostrando o rol que teve a educação para os atores sociais mais relevantes, os principais problemas que tinham que solucionar e as dificuldades que tinham que enfrentar para realizar esta tarefa. Ademais, se expõe o conteúdo e a significação que adquiriu a educação no desenvolvimento do país. Finalmente, se analisam brevemente os aspectos apresentados em relação a alguns dos temas chave do debate do bicentenário no qual estamos inseridos na atualidade.

Palavras-chave: política educacional chilena, educação pública, problemas educacionais do século XX.

1 Andrés Donoso es Antropólogo Social y Magíster en Estudios Latinoamericanos (U. de Chile). Colaborador del Archivo Etnográfico Audiovisual de la Universidad de Chile y doctorante de la Universidad de Sao Paulo. El artículo fue escrito en el marco de una estancia de investigación realizada en el Instituto Interuniversitario de Iberoamérica de la Universidad de Salamanca, gracias al financiamiento de Fundación Carolina, correo sdonoso@usp.br Sebastián Donoso es Dr. en Educación y académico del Instituto de Investigación y Desarrollo Educacional de la Universidad de Talca, e Investigador Asociado del Centro de Investigaciones Avanzadas en Educación, 


\section{INTRODUCCION}

Ante la proximidad del hito que marca el Bicentenario como nación, la revisión de algunas de las principales discusiones educacionales realizadas durante el período del Centenario, a saber: fines del siglo XIX y primer cuarto del siglo XX; siempre desde el marco de la política educacional, dan espacio a una reflexión sobre la permanencia en el tiempo de algunas temáticas, como también respecto de la emergencia de nuevos tópicos al tenor de las demandas que se han venido planteando.

El debate educacional en el centenario se centró - esencialmente- en la transformación de la educación desde un rol afuncional a los objetivos del desarrollo de la sociedad nacional, hacia el desempeño de un papel clave en la vigencia e implementación del proyecto de sociedad. En este camino se enfrentan diversas visiones sobre la finalidad última de la educación, como también sobre su implementación, evidenciando énfasis que aún en la actualidad se mantienen en controversia, a saber, nuevos conceptos arraigados en estos aspectos, tales como: el papel del Estado en esta tarea, la economía política de la educación (derecho a la educación y ciudadanía), la complejidad de implementar metas simultáneas de cobertura y calidad, y otros aspectos de igual relevancia que bajo léxicos diferentes han estado presentes en los 100 años de "desarrollo educativo" que median entre ambos hitos.

En el período que transcurre entre el Centenario y el Bicentenario, la revisión de los resultados del sistema escolar chileno, a la luz de los criterios que actualmente se denominan eficiencia interna y externa, muestra importantes cambios en sentido positivo. Ciertamente, se ha avanzado significativamente en estos indicadores, sin perjuicio de lo cual algunos aspectos siguen pendientes, dada la complejidad que revisten, como son: la incorporación y permanencia en el sistema escolar de la población más vulnerable, la orientación del currículo (instrumental/vocacional), la organización de la escuela, la sustentabilidad financiera del sistema, la formación de los docentes, etc. los cuales adquieren nuevas dimensiones y énfasis según la época en cuestión.

El texto analiza los principales temas y problemas educacionales y su discusión en el período señalado, dando cuenta de ellos en el siguiente orden: en primera instancia se observa el debate por el nuevo estatus de la educación en la sociedad del Centenario; en razón de ello, los temas y problemas en debate, para luego realizar un recuento de las transformaciones más relevantes inauguradas a principios del siglo XX. Finalmente se sintetizan algunos elementos y se discuten, ahora, desde la perspectiva del Bicentenario.

\section{EL NUEVO ESTATUS DE LA EDUCACIÓN}

Aunque la educación gozó de alta estima en occidente entre políticos e intelectuales educacionistas, al menos desde el advenimiento del pensamiento ilustrado, fue sólo en el intersiglo XIX-XX que ella empezó a comprenderse y vivirse como algo fundamental por el conjunto de nuestra sociedad, pasando de ser un tema de algunos a un tema de muchos. Esta alta estima de la educación hizo que los actores e intelectuales que por esos años reflexionaron al respecto, compartieran el mismo supuesto: la educación es buena y deseable por sobre todas las cosas. De lo que se desprendía la convicción de que ésta debía promoverse, fomentarse y/o mejorarse. La educación adquirió así halos 
sagrados y la escuela comenzó a comprenderse como un altar que debía ser visitado con regularidad.

La bondad de la educación era tan aceptada que aunque pudiese ser usada con fines asociales, como por ejemplo "facilitar el hecho de que algunos aprendiesen a delinquir de manera más eficaz”, ello se entendía como un riesgo que había que asumir, pues sus ventajas comparativas -en lenguaje de hoy, sus externalidades positivas- se apreciaban como inmensamente superiores a sus costos. Para ilustrar esta idea Nicolás Palacios, en su libro La Raza Chilena aparecido en 1904, expresó: "No hemos de suprimir los ferrocarriles porque los bellacos los aprovechan para huir de los jueces". (Palacios, 1904: 333). De igual forma, Alejandro Venegas (Valdés Canje) (1910: 264), Luis Emilio Recabarren (1910: 198) y Luis Galdames también coincidieron en sus planteamientos con Palacios. Siendo Luis Galdames, en su texto Educación Económica e Intelectual, de 1912, quien refirió de manera más clara a la alta valoración que adquirió la educación en los años del centenario:

"En medio de esta situación, que es delicada; delante de las incertidumbres del porvenir nacional, surje mui adentro de todos nosotros i por encima de todas las cosas, algo como una luz que nos alienta i guía: es la fe en el poder de la educación, en su virtud regeneradora, en sus impulsos creadores; la fe en el maestro que pone su alma fuerte i viril en el alma de la juventud, la fe en las enerjías de la raza i en nosotros mismos" (Galdames, 1912: 234).

Las razones que acompañaron esta fe inconmensurable en la educación fueron sacadas de las distintas perspectivas presentes en el ambiente intelectual del continente y que tenían en común la procura del progreso. José Abelardo Núñez, en 1889, en el marco del Congreso Nacional Pedagógico, expresó una asociación entre educación y progreso que hasta hoy es muy extendida: "Si la misión que cada criatura trae al mundo es la de perfeccionarse, progresar i contribuir al mismo tiempo al perfeccionamiento i progreso social, es solo la educación el medio que le permitirá alcanzar tales fines" (Núñez, 1890: 185).

La importancia de la educación también se apoyó en la idea de que ella era un imperativo ineludible para que el pueblo pudiera hacer efectiva su soberanía. Este argumento, presente en las élites independentistas desde comienzos del siglo XIX, se actualizó ahora en la voz de distintos sectores de la sociedad, incluidas las organizaciones de los sectores populares. Ello se ilustró, por ejemplo, en las conclusiones del Congreso Social Obrero de 1909, cuando se señaló que: "La armonía y concordia social no pueden establecerse sino con el advenimiento de la democracia y el gobierno del pueblo por el pueblo no será jamás verdad en la vida nacional, si no se proporciona a todos los llamados a ejercer los derechos y a cumplir las obligaciones del ciudadano, la preparación indispensable por medio de la educación universal del pueblo" (en Illanes, 1991: 64).

La educación se valoró, también, porque iluminaría a los sectores populares y les erradicaría su barbarie. Ello se ajustaba a la deprimida apreciación que tanto profesores, funcionarios públicos como intelectuales tenían de las personas carentes de educación, al extremo de considerarles, muchas veces, como potenciales criminales. Esto es destacado por Loreto Egaña cuando señala que "la opinión que tenían los visitadores respecto de los sectores más pobres, era similar a la que tenían los educacionistas y en general la élite del país. La mirada hacia estos sectores marcada por el desprecio y la distancia [...] estará presente también en el ámbito escolar. La propuesta cultural de la escuela, 
sin duda era lejana a la cultura de esos sectores pero, también, era reprobadora" (Egaña, 2000: 241). Esta opinión fue verbalizada en la época, entre otros, por el parlamentario Pedro Bannen, quien en 1902 expuso que la educación primaria obligatoria no afectará a las "clases cultas, ni aún a nuestra clase menos elevadas que tengan hábitos de moralidad $i$ de orden social. Irá solo en amparo de aquellos infelices niños cuyos padres, por indolencia o depravación, los dejan abandonados a la ignorancia, de aquellos que viven $i$ se desarrollan en un campo social lleno de vicios, de malos ejemplos i de perversas costumbres, en un terreno bien preparado para la jerminación de futuros criminales" (Bannen, 1902: 154). Estuvo presente -también- en intelectuales de la talla de Luis Galdames, quien señaló: "es urgente redimir a nuestras multitudes de la semi barbarie en que el analfabetismo las mantiene i en el cual la mugre las consume” (Galdames, 1912: 217).

La imagen subvalorada de la población que carecía de educación también permeó a los mismos sectores populares. Sus dirigentes demandaron más educación para así poder progresar, para estar en condiciones de ejercer su legítima soberanía, y para acabar con su ignorancia y barbarie. Así se trasluce de las palabras de Luis Emilio Recabarren cuando en su texto Ricos y Pobres, de 1910, enunció: "El conventillo y los suburbios son la escuela primaria obligada del vicio y del crimen. Los niños se deleitan en su iniciación viciosa empujados por el delictuoso ejemplo de sus padres cargados de vicios y de defectos. El conventillo y los suburbios son la antesala del prostíbulo y de la taberna" (1910: 174).

Todo el entramado de valoraciones que tuvo la educación en los años del centenario en Chile se escenificó en la discusión concerniente con la obligatoriedad de la instrucción primaria. Antigua controversia que se remontaba hasta el período independentista y que ya a fines del siglo XIX presentaba un importante grado de consenso a su favor, aunque se entendía que aún no existían los recursos suficientes para implementarle. Lo cual quedó reflejado en las conclusiones del Congreso Nacional Pedagógico de 1889, que sostuvo: "No existiendo aún elementos suficientes para hacer efectiva la enseñanza primaria obligatoria i no siendo posible improvisarlos, el Congreso cree que su implantación absoluta e inmediata, aspiración mui lejítima en sí, no es realizable ahora en el país" (1890: 191).

Esta vasta densidad argumental, sumada a este amplio consenso político, se conjugó con la serie de cambios sociales y económicos que se sucedieron en Chile desde el último tercio del siglo XIX, permitiendo que la instrucción primaria fuera legalmente obligatoria en el año 1920. Lo mismo, pero desde otro punto de vista, los argumentos y consensos no fueron en sí mismos suficientes para decretar la obligatoriedad de la educación primaria; ello tiene lugar como consecuencia de las transformaciones socioeconómicas que vivió el país y que obligaron a que grandes sectores de la población a demandar la ampliación de la cobertura educacional. Es entonces un proyecto político de envergadura y significación (Egaña, 2004).

Las transformaciones socioeconómicas que hicieron que en esos años la educación adquiriese el carácter de un bien vital para amplios sectores de la población chilena que se relacionaron con los adelantos en los medios de transporte. Principalmente por la introducción de la energía a vapor y la utilización del hierro tanto en barcos como ferrocarriles, los cuales impulsaron la urbanización de nuestra sociedad al inaugurar un proceso sostenido de migración campo-ciudad, lo que redundó en que hubiese un 
crecimiento explosivo de la población en pueblos, puertos y ciudades, y que se desarrollaran nuevas formas de producción, de corte industrial. Ambos procesos, urbanización e industrialización, hicieron ineficientes los procesos de socialización tradicionales, debido principalmente a que los adultos no conocían el emergente escenario que debían enseñar. La educación formal se comprendió, por tanto, como el principal medio de socialización y se entendió que ella debía ser realizada por especialistas que contaran con los conocimientos y recursos necesarios para tan delicada función.

Los conocimientos que sólo la escuela podía entregar, y que fueron fundamentales para el desenvolvimiento de los individuos en la nueva sociedad, fueron la lectoescritura, las matemáticas básicas y una plataforma cultural común que permitiera a las personas provenientes de distintas tradiciones comunicarse, organizarse, convivir y dar vida a una nueva comunidad, la comunidad nacional. El rol instrumental de la educación se fortaleció con el progreso técnico, no en vano en las disputas del centenario entre Valdés, Galdames y Encina esta materia forma parte del nudo central en torno del cual se erigen las diversas posturas político-educacionales. Este aspecto no será resuelto en forma satisfactoria por las Reformas educativas siguientes (1928, 1985, 1980, 1995), siendo constantemente un punto en debate superado con equilibrios muy precarios entre el rol instrumental y el rol de meta educacional que asume la educación (Donoso y Schmal, 2009). El espíritu de esta comprensión fue bien expresado por Pedro Bannen: "un hombre sin los conocimientos de la lectura i la escritura se encuentra en un país culto en situación análoga a la de un sordomudo entre los que no están privados del uso de la palabra" (Bannen, 1902: 152). Esta línea interpretativa es trabajada por varios investigadores de la historia de la educación chilena que se dedican al estudio de este período, entre los que destacan Patrick Barr Melej (1998: 73 y 74), Loreto Egaña (2000, 123) y Mario Monsalve (1998: 208). Siendo palabras de éste último las más adecuadas para dimensionarle:

\begin{abstract}
"El discurso educativo por el cual bregaron políticos y educacionistas pasó a ser asumido por aquella parte del sector popular que, producto del desenvolvimiento económico del país, había sido insertado en las más modernas actividades productivas. Aparte de los 'trabajadores de cuello blanco', las organizaciones de trabajadores de la minería y manufactura requerían de la instrucción, como instrumento que rompía el aislamiento, generaba comunicación e información, con lo cual el mensaje masificador podía ayudar a elevar la moralidad de la masa y los niveles de organización, a la vez, proporcionarle a ésta el contenido doctrinario que le permitiría formar conciencia para actuar en la lucha por sus reivindicaciones. Los partidos políticos, principalmente los que representaban intereses de los trabajadores, difundían un discurso que resultaba complejo para el nivel cultural de la masa, por lo tanto, la lectura y la escritura constituyeron instrumentos para la formación de cuadros dirigenciales, los que, además de heroísmo, debían tener la capacidad de comprender las bases científicas en que se fundaban las nuevas ideologías, para de este modo dar dirección a la masa laboral" (Monsalve, 1998: 137).
\end{abstract}

La necesidad de entender este nuevo escenario social y económico hizo que aumentase la demanda educacional por parte de los sectores medios y populares, lo que produjo que los indicadores educativos se multiplicaran considerablemente en los cincuenta años que transcurren desde 1880 a 1930 . En el éxito de esta empresa fue fundamental el aumento progresivo del gasto público en educación, derivado del incremento de los ingresos fiscales gracias a la inserción económica internacional devenida con la industrialización, lo que 
incidió directamente en el incremento del número de profesores, alumnos e instituciones educacionales $^{2}$, principalmente en lo que refiere a la educación primaria ${ }^{3}$. Darío Salas, en su texto El Problema Nacional, de 1917, entrega información útil para apreciar el crecimiento educacional de los años que rodearon al centenario.

\section{Tabla 1}

Indicadores de crecimiento educacional del intersiglo XIX-XX en Chile

\begin{tabular}{|c|c|c|c|c|c|c|}
\hline Años & $\begin{array}{c}\text { Escuelas } \\
\text { fiscales }\end{array}$ & Matrícula & $\begin{array}{c}\text { Presupuesto } \\
\$\end{array}$ & $\begin{array}{c}\text { Porcentaje } \\
\text { de letrados } \\
\text { (los que leen) } \\
\text { en la población } \\
\text { total }\end{array}$ & $\begin{array}{c}\text { Porcentaje } \\
\text { de letrados } \\
\text { (los que leen) } \\
\text { en la población } \\
\text { mayor de } \\
5 \text { años }\end{array}$ & $\begin{array}{c}\text { Presupuesto por } \\
\text { estudiante }\left(^{*}\right)\end{array}$ \\
\hline 1865 & 599 & 39.236 & 234.340 & 17 & 24 & 5,9 \\
\hline 1875 & 818 & 65.875 & 472.870 & 22,5 & 28 & 7,1 \\
\hline 1885 & 826 & 68.894 & 753.100 & 28,8 & 34 & 10,9 \\
\hline 1895 & 1.248 & 114.565 & 1.861 .500 & 31,9 & 38,1 & 16,2 \\
\hline 1905 & 2.099 & 159.379 & 5.727 .115 & 40 & 47,2 & 35,9 \\
\hline 1915 & 2.920 & 308.113 & 14.950 .922 & 46 & 52 & 48,5 \\
\hline
\end{tabular}

Fuente: Darío Salas, 1917: 32.

(*) Incluidos por autores.

Para cerrar este apartado, se enfatiza que en los años del centenario la educación, más específicamente la escuela primaria, aumentó de manera considerable su legitimidad entre los sectores populares, quienes le comenzaron a valorar y demandar decididamente, superando algunas dudas sobre la legitimación social que la había acompañado en sus inicios, producto de la desconfianza de los sectores sociales populares ante el "adoctrinamiento" de las ideas conservadoras que suponía la masificación de la enseñanza, Acompañando esta sensibilidad hubo una mejora de la infraestructura educacional y una decidida preocupación por profesionalizar la labor docente, la que concomitantemente fue acompañada de mejores remuneraciones (Núñez, 2007). A su vez, estos elementos hicieron que cambiaran los papeles relativos al control del proceso educacional, pues, si antes eran los estudiantes, los padres o apoderados quienes decidían el cómo y cuándo estudiarían los pupilos, ejerciendo muchas veces su decisión con prepotencia y desdén hacia el trabajo educacional del maestro, a comienzos del siglo XX era el profesor la

2 No obstante, se debe hacer la salvedad que el aumento en los índices no significó necesariamente un aumento en la calidad de la oferta educativa, así como tampoco una mejora en los resultados, la asistencia y la deserción de los estudiantes, los cuales fueron apreciados recurrentemente como insatisfactorios.

3 Para observar el aumento en la educación secundaria y técnica acúdase a Labarca (1939: 241, 242 y 249). 
persona que más sabía de dicho tema. Al respecto Loreto Egaña señala que hubo: "Un cambio en la actitud de los padres ante la escuela, a medida que avanza el siglo [XIX], que se traduce en menor opinión y mayor aceptación; esto constituye la contraparte de un aumento de la autoridad de la escuela, en cierta medida de una legitimación de su acción" (2000: 183).

\section{DISCUSIONES EDUCACIONALES EN LOS AÑOS DEL CENTENARIO}

Durante las dos primeras décadas del siglo XX se llevó a cabo en el país una vasta discusión que consideró actores políticos, gremiales y sociales, la cual derivó en la Ley de Instrucción Primaria Obligatoria promulgada en 1920. De ella se han distinguido cuatro ámbitos que, descritos en profundidad, sirven para apreciar las particularidades de los debates educacionales presentes en el centenario del país. Estas dimensiones son las vinculadas a la orientación que debía poseer la educación, a lo deseable que era aspirar a tener una población más educada, al interés real que evidenciaban los mismos sectores populares por asistir a la escuela y al papel que debía asumir el Estado en el proceso de implementación de la ley.

Respecto del primer ámbito, la orientación que debía poseer la educación se anota que desde Manuel de Salas y la Academia de San Luis hasta las discusiones educacionales del centenario, hubo varias opiniones relativas a la necesidad de que la educación fuese más práctica en la búsqueda de ésta y que fuese de mayor utilidad para la gran mayoría de los estudiantes que -una vez que egresaban- no se dedicaban a las leyes, al gobierno y/o a las mismas labores educacionales. Claudio Matte, en 1888, ya anticipada las opiniones que tanto Francisco Encina como Luis Galdames defenderían en el Centenario. Pensaba que la educación era demasiado teórica, lo que alentaba la vanidad del estudiantado y hacía que, a la larga, estos despreciaran las labores manuales que desempeñaban sus padres y que con toda seguridad muchos de ellos deberían cumplir más adelante:

"Desde hace tiempo se manifiesta en Chile una tendencia decidida a hacer la Instrucción Primaria más práctica, a ponerla mas en conformidad con las necesidades del pueblo. La enseñanza es demasiado teórica, se dice; no ejerce bastante influencia sobre los niños i a menudo la ejerce mal pues no son raros los casos en que solo desarrolla la vanidad, haciendo que, al dejar la escuela, después de dos o tres años de estudios, con una pequeña suma de conocimientos mal dijeridos, los niños se crean mui superiores a los círculos de donde han salido i consideren deshonrosas las ocupaciones modestas de sus padres. Al terminar sus estudios, los alumnos no poseen ninguna preparación para la vida práctica; su intelijencia se ha desarrollado poco, i los escasos estudios que han hecho en la escuela les inspiran el deseo de ocuparse en una oficina o de obtener un destino cualquiera, antes de dedicarse a una ocupación que requiera trabajo físico. / La instrucción, en tales casos, léjos de hacer más feliz al individuo, lo hace mas desgraciado, puesto que por una parte le da aspiraciones escesivas, $i$ por la otra, lo deja sin los medios de satisfacerlas, de donde resulta una lucha interna a que solo los fuertes resisten sin doblegar su carácter" (1888: 180).

Agregando,

“La enseñanza, comprendida de esta manera, da, pues, resultados prácticos, porque al mismo tiempo que perfecciona al individuo moralmente, lo coloca en mejor situación para aprender una profesión u oficio i satisfacer así sus necesidades materiales" (1888: 182). 
Francisco Encina, en 1911, en su libro Nuestra Inferioridad Económica, enuncia nuevamente esta posición al subrayar que la educación tal y como se daba prescindía "del vigor físico, del desarrollo de las aptitudes económicas, de la moral y del carácter, esto es, de todo lo que conserva al individuo y a la especie y hace posible una civilización robusta”. (1911: 147). Un año después, Luis Galdames comentando el trabajo de Encina, al compartir dicho diagnóstico se pregunta ¿qué hacer entonces?, respondiendo: "Tratar de suprimir o atenuar cuanto sea posible esa falta de preparación i de aptitudes de nuestro pueblo para la vida manufacturera, fabril i comercial. I esa es la obra reservada a la educación" (1912: 42).

Pero la opción por una educación más práctica no era mayoritaria ni tampoco se impuso. También estaban quienes pensaban que el carácter humanista de la educación era el adecuado y lo que hacía falta era su mejora. Ello fue lo que propusieron, entre otros, Valentín Letelier, Luis Emilio Recabarren y también la Asociación de Educación Nacional (fundada en 1904 e integrada, entre otros, por José Abelardo Núñez y Darío Salas).

Valentín Letelier, cuya obra clásica Filosofía de la Educación fue editada muy temprano, en 1892, para volverse a imprimir nuevamente tras casi cuarenta años, es uno de los máximos exponentes de la perspectiva reformista de la orientación humanista de la educación. En el fondo, el pensaba, que los males educacionales se producían por una deformación de ella misma, que la conduce a privilegiar la instrucción por sobre la educación. Es decir, la memorización por sobre el aprendizaje significativo (Letelier, 1927: xxi). Desdeñando los fines prácticos de la educación Letelier señala: "El fin de la educación, contemplada en su más noble aspecto, no es el de asegurar a los educandos los medios de hacerse ricos. Sin que le sea lícito eximirse del deber de adiestrar sus facultades para el trabajo, el fin que ella debe perseguir es el de formarlos para la sociedad en que han de vivir" (1927: 152).

Luis Emilio Recabarren, por su parte, pensaba que el carácter humanista que tenía la educación no era un problema, sino el que los sectores populares no pudieran poner en práctica dichos conocimientos debido a que en sus labores cotidianas ella no era adecuadamente requerida. Esta suerte de disociación entre lo enseñado por la educación y las necesidades de la sociedad hacía que ella no aportara a nobles fines sino, al contrario, sirviese para que los sectores populares vendieran su conciencia. Afirmando al respecto que, para la "última clase de la sociedad el saber leer y escribir, no es sino un medio de comunicación, que no le ha producido ningún bienestar social. El escasísimo ejercicio que de estos conocimientos hace esta parte del pueblo, le coloca en tal condición que casi es igual si nada supiese. En las ciudades y en los campos, el saber escribir, o simplemente firmar, ha sido para los hombres un nuevo medio de corrupción, pues, la clase gobernante les ha degradado cívicamente enseñándoles a vender su conciencia, su voluntad, su soberanía” (Recabarren, 1910: 168-9).

El segundo ámbito distinguido de la discusión sobre la Ley de Instrucción Primaria Obligatoria tiene que ver con la pregunta ¿están los sectores populares interesados en

4 Iván Núñez asevera que la Asociación Nacional de Educación buscaría lo mismo, al afirmar que ella "rechaza el tradicional reduccionismo que identifica ‘educación' con ‘instrucción’ y pone énfasis en la educación como formación integral y no como mera impartición de conocimiento” (Núñez, 1986: 31). 
que sus hijos reciban instrucción primaria? Este cuestionamiento fue de los más lúcidos del período, pues denotó un esfuerzo por ponerse en el lugar de los beneficiarios de la discusión que se llevaba a cabo. Durante gran parte del siglo XIX el desinterés de los sectores populares por educarse fue evidente, sea porque los locales educacionales eran precarios, porque muchas veces se vejaba a los estudiantes más pobres o porque sencillamente la educación no estaba dentro de sus prioridades ${ }^{5}$. Esta indiferencia se reflejaba, entre otros aspectos, en la alta inasistencia y deserción escolar que reinaba inclusive en los años del centenario. Claudio Matte explica al respecto:

\begin{abstract}
"Para buscar medios de evitar que la asistencia a las escuelas sea tan poco constante como es en la actualidad, creo que es indispensable estudiar cuales son las causas de la irregularidad que se trata correjir. / Estas causas son, a mi juicio, de doble naturaleza. Las unas tienen su orijen en las escuelas mismas, en sus defectos de organización, instalación, ubicación, etc.; las otras lo tienen en las clases llamadas especialmente a servirse de estas escuelas, en sus escasos hábitos de orden y perseverancia, en wsu poca apreciación de los beneficios que reportan de la instrucción” (Matte, 1890: 189).
\end{abstract}

No fueron pocos los que intentaron explicar esta apatía de los sectores populares como consecuencia de su ignorancia y salvajismo. Las palabras de Pedro Bannen muestran ese sustrato: "al hacer el reclutamiento de estos niños en sus propias habitaciones se ha tropezado en la mayor parte de los casos con la resistencia más tenaz e injustificada de sus padres, resistencia que no tiene más esplicación que la de crasa ignorancia $i$ la desgraciada depravación en que viven. Prefieren que sus hijos vaguen en las calles $o$ en los basurales antes que permitir que asistan a una escuela que ellos consideran como algo absolutamente innecesario si no como una prisión o un castigo" (Bannen, 1902: 155).

Por su parte, otros pensaron que el desdén de los sectores populares hacia la escuela tenía que ver con el hambre, lo que obligaba a los pequeños a trabajar para aportar con ello a la sobrevivencia del grupo familiar. Darío Salas fue uno de los convencidos de que esta era la explicación fundamental, señalando: "por cierto, en nuestro país, no son los defectos y la enfermedad propiamente tal los únicos factores de este orden que influyen sobre la inasistencia, la eliminación, los fracasos y los retardos: la miseria fisiológica, la mala alimentación, la fatiga producida por el trabajo físico, los malos hábitos, aportarán también un grueso contingente" (Salas, 1917: 191). Esta línea argumental es desarrollada extensamente por María Angélica Illanes, quien comprende que "la necesidad de sobrevivencia de los sectores populares, en el marco de una economía en crónica crisis pauperizadora, vaciaba las escuelas de los niños trabajadores que copaban las calles, las faenas, las fábricas, puertos y cárceles. La escolarización naufragaba, una y otra vez, y se entregaba a la fuerza de la deserción" (Illanes, 1991: 16). Agregando:

"No sólo los niños que no asistían a las escuelas tenían hambre. Los que iban a las escuelas públicas también la tenían. Los niños proletarios escolares estaban pálidos, flacos, demacrados, somnolientos. Mal alimentados, desabrigados, faltos de aire y sol, viviendo en cuartuchos apiñados más bajos que la misma calle, en el abandono de la pobreza y la desmoralización. El salario del padre no alcanzaba y muchas veces se quedaba en el bar" (Illanes, 1991: 71).

5 Sobre las precarias condiciones y tratos vejatorios señalados, consúltese Egaña (2000: 35, 42 y 132). 
El tercer ámbito que se distinguió de la discusión sobre la Ley de Instrucción Primaria Obligatoria tuvo relación con los intentos por dilucidar si era conveniente, en términos políticos y económicos, brindar educación a los sectores populares. Esta duda fue alimentada por algunos sectores de la élite que pensaban que el tener un pueblo más educado no traería necesariamente beneficios económicos para el país, al mismo tiempo que sospechaban que una mayor instrucción popular traería descontrol, pues les proveería perspectivas críticas que utilizarían para analizar su actual estado de postración o bien les daría altas expectativas de vida que la sociedad no podría satisfacer. Las palabras del parlamentario Manuel Salas, en 1905, son una buena expresión de estas preocupaciones:

\begin{abstract}
“¿De qué sirve en tales condiciones lo que el Estado gasta en la instrucción popular, si ella ningún fruto puede dar, desde que a su enseñanza se opone el ejemplo corruptor? ¿A qué vienen los conocimientos en hijiene que se trata de vulgarizar si se obliga a las personas a vivir aglomerados sin distinción de sexo ni edades, en habitaciones estrechas, infectas $i$ oscuras? ¡A solo para hacer más dura la situación presente! ¡Para que estén en mejor aptitud de renegar contra la sociedad! ¡Para que jerminen las malas posiciones, las huelgas, el anarquismo!" (Salas, 1905: 160).
\end{abstract}

Quienes diferían de esta posición afirmaban que la mayor instrucción de la población redituaría más beneficios económicos que problemas de descontrol y, en la misma lógica que se presentase de Palacios al inicio de este artículo, pensaron que no porque una mayor educación conlleve riesgos, en este caso para el orden interno, ella no debía promoverse. El parlamentario Torrealba señaló:

"Su Señoría manifestó que aun cuando fuera indispensable recurrir a las contribuciones o que el Estado contratara un empréstito para costear los gastos que demande la lei, ésta debía despacharse, porque responde a una necesidad i a un bien innegable para el país. El ciudadano que sin instrucción produce uno, instruido i preparado para las artes, para las industrias, para el comercio, producirá por dos, tres o cuatro, i esta mayor producción de cada hombre beneficiará naturalmente al Estado" (Torrealba, 1919: 166).

Cabe señalar que la fuerte demanda social por educación primaria implicó que el argumento asociado al resguardo del orden cambiara. La exigencia hizo, desde estos años, que el orden sólo pudiese ser mantenido aceptando la ampliación de la educación primaria, al menos en términos legales: "Así, la escuela, como construcción histórica del siglo XX, se levantó, ante el temor al socialismo, como uno de los pilares sobre los cuales había de emerger un nuevo orden social llamado a incorporar al pueblo y, en especial, a los hijos de la clase trabajadora, a los beneficios del sistema” (Illanes, 1991: 15).

La última de las aristas tomada de la discusión legal es sobre el papel que el Estado debía asumir en la implementación de la instrucción primaria obligatoria. Las dimensiones involucradas en este asunto fueron muchas, siendo las más vehementes aquellas que sostenían que el Estado no debía obligar a las personas a educarse, no podía imponer una perspectiva valórica y no debía ir en desmedro de los emprendimientos educacionales privados.

Ante el nuevo protagonismo que podía adquirir el Estado, de materializarse la instrucción primaria obligatoria, se levantaron posiciones doctrinarias, de corte ultraliberal, 
que se opusieron a la iniciativa al entender que el Estado coaccionaría al individuo y las familias al obligarles a asistir a la escuela, pensando ellos que el Estado debía estar al servicio de las personas y no transformarse en un agente de su sujeción. Los parlamentarios Ventura Blanco y Walker Martínez fueron de esta opinión. Ventura Blanco sostuvo: "Que el padre de familia tenga el deber de educar a sus hijos, de criarlos, de enseñarlos a ser buenos ciudadanos i buenos cristianos, no es un antecedente para decir que está obligado a mandarlos a las escuelas. Si tuviera esta obligación, por virtud de las leyes citadas, también podría decirse que podrían establecerse cunas públicas para dar buena leche a los niños $i$ que las madres estaban obligadas a llevar a sus hijos a tomar ese alimento" (Blanco, 1902: 156). Walker Martínez pensaba, a su vez: "La obligación de darla el Estado no envuelve la idea de imponerla; la vijilancia de la familia no envuelve la idea de permitir al padre el abandono de sus hijos, i la dirección relijiosa no envuelve la idea de imponer por la fuerza las convicciones de la doctrina. / Esta armonía determina el alcance de los derechos i deberes que de allí se desprenden. Su exajeración, de cualquier parte que sea, es la consagración del absurdo" (1902: 158).

En respuesta a estas argumentaciones, Pedro Bannen puso en evidencia lo acomodaticias que resultaban al recordar la temprana aprobación de la ley de Servicio Militar Obligatorio que tenía similares implicaciones educacionales; sin embargo, no levantó las mismas dudas o sospechas. Sus palabras son elocuentes:

"Ahí esta la ley del servicio militar obligatorio (aprobada en 1900). Estoy cierto que los $H$. Senadores que hoy impugnan este proyecto sobre instrucción primaria también obligatoria, votaron aquella ley sin escrúpulos ni vacilaciones, con plena conciencia de que procedían bien, probablemente con íntima satisfacción y sin acordarse del derecho del padre a quien se le arrebataba el hijo, ni de la libertad de enseñanza, sabiendo que forzosamente se da la instrucción elemental en los cuarteles, ni del despotismo del Estado, de la eficacia o ineficacia de la ley, ni de tantas cosas que hemos oído ahora" (en Illanes, 1991: 41).

Intimamente relacionada era la postura de quienes no deseaban que el Estado pudiese transformarse en el principal agente educacional, pues ello conllevaría el riesgo de otorgarle la capacidad de detentar un monopolio del poder ideológico y/o doctrinal. Ellos temían, en el fondo, que la educación pública se transformase en expresión de los intereses del gobierno de turno, o sea, finalmente, que fuera educación oficial. Esta duda fue planteada por Claudio Matte en estos términos: "I cuál es la escuela que se quiere imponer a los hijos del pueblo? I cuál es esa instrucción? ¿Es ella tal i como lo desea nuestro pueblo, amoldada a su índole, costumbre, necesidades i sentimientos? ¿No puede ella prestarse a una propaganda sectaria?" (en Egaña, 2004: 21). Estas mismas dudas fueron expresadas en forma de certeza en el año 1902, en la Revista de Escuelas Católicas, cuando se afirmó: "Creemos que no andamos desacertados al decir la instrucción primaria de hecho no será sino instrucción oficial obligatoria” (1902: 196).

Por último, se esgrimía fuera de toda lógica o estrategia argumental, que la educación primaria obligatoria acabaría con la educación privada. Cuestión que no estuvo nunca en agenda, pero de todas maneras se previno. Así la misma Revista Católica sostuvo: "Establecida la instrucción obligatoria, la actividad privada quedará reducida a cero. Va a suceder con la instrucción obligatoria lo mismo que acontece con las industrias pequeñas, las cuales pueden subsistir mientras no venga una gran fábrica, que concluya con todas ellas. El Estado abrirá escuelas en gran escala; y con ello, lejos de facilitar la 
difusión de la instrucción privada que, además de ser economía para el fisco, es mejor y más delicada que la oficial, concluirá con el colegio particular" (1902: 196).

Muy distinta fue la opinión que expresó Alejandro Venegas cuando en su texto Sinceridad, Chile Íntimo en 1910, criticó la educación privada y confesional al sostener: "Escondidas tras el fantasmon de la libertad de enseñanza, las congregaciones religiosas i los comerciantes en instruccion, disfrutan hoi dia de una libertad que raya en licencia $i$ que ha dado como resultado el que se esté engañando pública e impunemente a millares de padres de familia i que la mitad de nuestra población escolar esté mareándose física i moralmente, en establecimientos de pseudo-educación” (1910: 342).

\section{LAS TRANSFORMACIONES EDUCACIONALES INAUGURADAS A PRINCIPIOS DEL SIGLO XX}

El nuevo estatus de la educación y las discusiones educacionales presentes en el Chile del Centenario se materializaron en tres transformaciones profundas en la educación: su masificación, su articulación en un sistema educacional y su orientación nacional.

La más vistosa de ellas fue el aumento de la cobertura educacional, principalmente de la instrucción primaria, aunque se debe precisar que dicho incremento no se debió tanto a mandatos legales sino a las transformaciones productivas que hicieron que la misma población exigiera mayores posibilidades educacionales. Por tanto, el aumento de la cobertura, si bien significativo en este período en la medida que refleja un cambio de tendencia, desde el desinterés educacional al interés manifiesto de grandes sectores de la población, sólo llegaría a abarcar porcentajes que se condecirían con su obligatoriedad en la década de 1960 (Cruz, 2002: 21).

Respecto de la segunda transformación se anota que en los años del Centenario se consolidó la necesidad de lograr coordinar a las distintas agencias y agentes educacionales bajo un sólo sistema, pues así se garantizaría la posibilidad de que todos los estudiantes pudiesen circular por la pirámide educacional en virtud de sus méritos (Palacios, 1904: 741; Galdames, 1912: 90), dado que hasta esa fecha había al menos dos sistemas educacionales inconexos, uno para los sectores populares, compuesto por una gran cantidad de escuelas primarias aisladas, y otro para las élites, que incluía preparatorias, liceos y universidades (Monsalve, 1998: 205). La supresión de esta dualidad se entendió como imperiosa, pues su mantenimiento sólo hacía, siguiendo las comprensiones del intelectual peruano José Carlos Mariátegui, que los estudiantes de sectores populares, por mucha inteligencia y capacidad que tuviesen, se vieran imposibilitados de acceder a los liceos o universidades, al tiempo que favorecía a los estudiantes de las clases altas que, independientemente de sus méritos, siempre accedían a los niveles mayores de instrucción (Mariátegui, 1925: 50).

Entre los que promovieron esta necesaria articulación del sistema educacional se contaron Letelier (1892: 630 y 631), Galdames (1912: ) y Salas (1917: 98). Lo mismo pretendió la Asociación de Educación Nacional (Núñez, 1986: 31) y algunas agrupaciones y federaciones obreras. De estas últimas se recuerda que, en un congreso obrero de 1905, se propuso la implementación de la Escuela Primaria Nacional Común (Illanes, 1991: 46), moción más representativa de esta postura y que siguió madurando con el siglo hasta 
lograr su máxima expresión en el Proyecto de Escuela Nacional Unificada del gobierno de la Unidad Popular a principios de la década de 1970. De todos los precursores de la articulación fue Galdames quien sintetizó más claramente esta propuesta:

"Dada la correlación necesaria entre todas las ramas de la enseñanza pública, la instrucción primaria i la superior tendrian que ser a la vez objeto de modificaciones sustanciales. La primera medida que vendria a imponerse, está desde hace tiempo señalada i se refiere a la armonizacion entre los estudios elementales de la escuela primaria i los estudios científicos del liceo, o sea, al establecimiento de la continuidad entre una i otra institución educativa. Por cierto, dentro de esta reforma, la preparatoria actual del liceo subsistiria, pero con el mismo plan de la escuela. / De este modo, el liceo, perderia el carácter aristocrático de que hoi se le tacha con indudable fundamento. La educación científica aprovecharia las mejores capacidades de nuestro pueblo, con evidente beneficio para el pais, i el liceo mismo tendria una base mucho mas amplia, para el desarrollo de su influencia i de su accion cultural" (Galdames, 1912: 201).

\section{Agregando:}

"Todas esas ramas de la educacion, reconociéndose vinculadas estrechamente por el fin común de la cultura i el progreso del pais, podrian unirse en un solo cuerpo; esto es, en un Consejo de carácter técnico en que todas ellas estuvieran representadas. Cada una se administraria por su Consejo especial, pero todos estos Consejos juntos constituirían la superintendencia de la educacion pública" (Galdames, 1912: 202).

La tercera transformación, relativa a que la educación debía tener una orientación nacional, también se consolidó en esos años. El discurso nacionalista, siempre amplio pero vago, y por lo mismo muy convocante y seductor (Donoso, 2008: 76 y 77), cundió en todas las esferas públicas y sociales desde fines del siglo XIX, siendo un discurso que vino a llenar los vacíos de sentido que produjeron los crecientes procesos de industrialización y urbanización; procesos que implicaron que muchas personas abandonaran sus tradicionales formas de vivir y trabajar y sobre las cuales nada podían decirle sus conocimientos tradicionales, tampoco sus amigos ni sus padres.

Valentín Letelier (1892: 160 y 658), Francisco Encina (1911: 244), Darío Salas (1917: 41) y Pedro Aguirre Cerda (1918: 171) fueron algunos de los intelectuales que proponían protagónicamente una educación de orientación nacional. La cual, por definición, debía arraigarse en lo propio y dar una imagen de una colectividad unida tanto en la historia como en sus proyectos. Luis Galdames -nuevamente- es quien más profundamente desarrolla este aspecto, aquí dos extractos que ilustran lo expuesto.

\footnotetext{
"Aplicando ahora estos conceptos a la educacion, lo que el nacionalismo desea, como ya otra vez tuve oportunidad de manifestarlo, es que en todos los colejios actúe 'un sujerimiento permanente de ideales, en armonía con nuestros recursos, con nuestras necesidades i con nuestras aspiraciones como pueblo; un conjunto homojéneo de doctrinas i de aspiraciones, capaz de determinar el rumbo de nuestra actividad individual"' (Galdames, 1912: 51).
}

"Lo dicho basta, sin embargo, para comprender que el nacionalismo educativo es algo mas amplio que el civismo i que el amor a la patria. Estos sentimientos inclinan a la actuación política o a la simple contemplación admirativa de las glorias nacionales; aquel tiene por objeto una acción constante en beneficio propio i colectivo, dentro de todos los órdenes 
de la actividad humana, según orientaciones jenerales sujeridas permanentemente. / Sólo así concurriremos a la formación de un espíritu nacional activo y fecundo" (Galdames, 1912: 52).

Su orientación nacional hizo que la escuela se transformase en forma paulatina en el "Altar de la Patria", poblándose de banderas, efemérides y actos de conmemoración cívica. Decididamente el discurso nacional fue impregnando todas las actividades escolares hasta transformarse en el principal referente identitario para el cual trabajaría la escuela. Aunque la vocación evangelizadora se mantuvo, ella perdió protagonismo en pos de la vocación nacionalista: al mismo tiempo que teocentrismo daba paso al antropocentrismo, los curas cedían su lugar a los profesores, las iglesias a las escuelas y los rezos a los himnos. La nación fue así el nuevo dios, a él se le debía reverenciar en las escuelas, éstas debían coordinarse bajo un único sistema y alcanzar a todos los niños del país. Esa fue la agenda educacional que se inauguró en los años del centenario y que se desarrolló durante todo el siglo XX.

\section{DEL CENTENARIO AL BICENTENARIO: PUNTOS EN DEBATE}

El sentido de la presente sección es evidenciar algunas ideas de convergencia y divergencia entre los debates y problemas del sistema educativo chileno del período del centenario con los que actualmente están en debate ad portas de cumplirse el Bicentenario, sin profundizar mayormente en este último, ya que implica abordar un objeto de estudio diferente al propuesto en el texto.

El protagonismo de la educación como factor clave del desarrollo ha ido crecientemente en aumento a medida que transcurre el siglo XX y nos aproximamos al Bicentenario. En este transcurrir, la escuela como institución se validó socialmente como un agente esencial para la socialización de la población en las pautas sociales e instruccionales indispensables para el ejercicio de la ciudadanía, como también en su inserción sociolaboral. Sin embargo, en el umbral del Bicentenario la institucionalidad escolar ha perdido reconocimiento e influencia. Este fenómeno, en cambio, no ha sido equivalente respecto de la educación como disciplina y herramienta de desarrollo individual y social. Por el contrario, la educación ha cobrado gran relevancia, en especial tras una triste la década de los 80, aunque la institución escolar sea la que se encuentre en crisis.

Concomitantemente, el optimismo que conlleva la educación como factor clave en el progreso personal y social, incluyendo en esta dimensión "la armonía social", se prolonga con énfasis en estos dos momentos desde el Centenario hasta nuestros días, aunque su expresión implica múltiples caminos y diversa institucionalidad. Pese a que la educación concebida como "un factor clave de desarrollo y la gran esperanza de la promoción social" es cuestionada fuertemente con el "movimiento pingüino del año 2006", no merma en grado sustantivo la confianza en ella como instrumento indispensable del desarrollo personal, social y económico, aunque cambia en un grado importante el énfasis desde una convicción más social -dominante hasta los años 70- hacia una más individual, fuertemente enraíza post los 80 .

Al igual que en el centenario, en la actualidad los componentes endógenos del desarrollo del sistema educacional se ven fuertemente tensionados por las demandas del 
desarrollo productivo y también científico tecnológico, sólo que bajo estadios de avance diferentes, siendo estos últimos un factor clave que demanda su actualización.

La insatisfacción que en el presente (Bicentenario) se ha manifestado por los resultados del sistema escolar, no tiene un parangón equivalente con lo acontecido en el Centenario, toda vez que el problema entonces era esencialmente diferente: ampliar de modo manifiesto la cobertura dado que sus estándares eran aún muy incipientes, mientras que este fenómeno en la actualidad ha cedido su lugar a la provisión de una educación de calidad para todos.

Por su parte, los debates políticos centrales sobre la orientación del sistema educacional y las medidas de gestión educativa y financieras para dar cumplimiento a estos objetivos son plenamente consistentes con los contextos de cada época, aunque sus tendencias sean comparables, y el problema sea genéricamente similar, sus escalas de trabajo son diferentes, dando origen a problemáticas de distinta envergadura y extensión que aquellas que enfrentó -en su momento- la Ley de Instrucción Primaria Obligatoria de 1920.

En el Bicentenario, la masificación del sistema escolar está circunscrita a la enseñanza preescolar, ya que para la enseñanza básica y en grado bastante alto en la enseñanza secundaria es un tema logrado (se excluye a la educación superior del análisis). En la actualidad el sistema escolar se encuentra articulado, sin perjuicio que haya que optimizarlo, flexibilizarlo y diversificarlo ante nuevas demandas de modernización. Finalmente, el éxito identitario alcanzado por el currículo escolar en el siglo XX se ha reorientado a una mayor pertinencia de la diversidad, donde los espacios locales y las realidades de cada contexto cobran especial fuerza en el contenido y forma de los proyectos educativos que se impulsan, con mayor convicción en que en esa capacidad de respuesta residen las bases del nuevo desarrollo postbicentenario.

Las discusiones educacionales en el Chile del Centenario constituyen un hito clave en el desarrollo del país. Es difícil pensar en el avance social, económico y político del país del siglo XXI si tras el Centenario no se hubiesen estado visualizando las grandes tareas de la educación como motor del progreso social y económico, como agente de desarrollo personal y social y como creador de identidad nacional, por mencionar algunos aspectos claves que permiten sustentar el rol determinante que adquiere desde el Centenario del país la educación en los proyectos de sociedad y en la construcción de los pactos sociales que otorgaron gobernabilidad al país.

En ambos períodos en análisis existen otras materias en debate que poseen una raíz más ideológica, y que responden a concepciones vinculadas a la vigencia de la educación estatal y particular, incluyendo en esta última el componente religioso, elementos que a su vez han estado presentes no sólo en estos momentos sino recurrentemente durante el siglo XX y también en los debates de este siglo XXI, al analizarse el proyecto de Ley General de Educación (2009) y con mayor fuerza aún al discutirse las ideas acerca de un eventual proyecto de Fortalecimiento de la Educación Pública (2008-2009), materias que en sí mismas concitan un análisis que supera los objetivos trazados en este trabajo. 


\section{BIBLIOGRAFIA}

Aguirre Cerda, Pedro (1918). "La Educación y su Aporte a las Tareas Nacionales". En: Monsalve, Mario (1998). "...I y el Silencio Comenzó a Reinar". Documento para la Historia de la Instrucción Primaria 1840-1920, DIBAM, Santiago de Chile, pp. 170-172.

Bannen, Pedro (1902). "Discurso del Senador Bannen en Sesión Ordinaria del 30 de julio de 1902". En: Monsalve, Mario (1998) “...I y el Silencio Comenzó a Reinar”. Documento para la Historia de la Instrucción Primaria 1840-1920, DIBAM, Santiago de Chile, pp. 152-155.

Barr Melej, Patrick (1998). "Patria y Pedagogía: Reformistas, Nacionalismo y la Búsqueda de una Respuesta a la Cuestión Social en la Educación Pública Chilena, 1904-1941". En: Revista SOLAR de Estudios Latinoamericanos, Federación Internacional de Estudios Sobre América Latina y el Caribe, pp. 73-86.

Blanco, Ventura (1902) "Argumento del Sector Conservador que Cuestiona la Propuesta de Hacer Obligatoria la Instrucción Primaria”. En: Monsalve, Mario (1998) “...I y el Silencio Comenzó a Reinar". Documento para la Historia de la Instrucción Primaria 1840-1920, DIBAM, Santiago de Chile, pp. 156-157.

Cruz, Nicolás (2002). El surgimiento de la Educación Secundaria Pública en Chile. 1843-1876 (El Plan de Estudios Humanista), DIBAM, Santiago de Chile.

Donoso, Andrés (2008) Educación y Nación al Sur de la Frontera, Pehuén Editores, Santiago de Chile.

Egaña, Loreto (2000). La Educación Primaria Popular en el Siglo XIX en Chile: Una Práctica de Política Estatal, DIBAM, Santiago de Chile.

Egaña, Loreto (2004). "Ley de Instrucción Primaria Obligatoria: Un debate Político". En: Revista de Educación, $\mathrm{N}^{\circ}$ 315, Ministerio de Educación, Santiago de Chile, pp. 14-29.

Encina, Francisco (1911). [1986] Nuestra Inferioridad Económica, Editorial Universitaria, Santiago de Chile.

Galdames, Luis (1912). Educación Económica e Intelectual, Imprenta Universitaria, Santiago de Chile.

Illanes, María Angélica (1991). Ausente, Señorita. El Niño-Chileno, la Escuela-Para-Pobres y el Auxilio, Chile 1890-1990, Junta Nacional de Auxilio Escolar y Becas, Santiago de Chile.

Labarca, Amanda (1939). Historia de la Enseñanza en Chile, Publicaciones de la Universidad de Chile, Imprenta Universitaria, Santiago, pp. 219- 265.

Labarca, Amanda (1943). Bases para una Política Educacional, Editorial Losada, S.A., Buenos Aires.

Letelier, Valentín (1892). [1927]. Filosofía de la Educación, Cabut y Cía. Editores, Buenos Aires.

Mariátegui, José Carlos (1925). "Enseñanza Única y Enseñanza de Clase". En: Mariátegui, José Carlos (1986) Temas de Educación, Editorial Amauta, Lima, pp. 49-56.

Martínez, Walker (1902). "Primero que Haya Escuelas, Para que Luego los Padres con Libertad Envíen a sus Hijos a Ella”. En: Monsalve, Mario (1998) “...I y el Silencio Comenzó a Reinar”. Documento para la Historia de la Instrucción Primaria 1840-1920, DIBAM, Santiago de Chile, pp. 158-159.

Matte, Claudio (1888). "La Enseñanza Manual en las Escuelas Primarias". En: Monsalve, Mario (1998) “...I y el Silencio Comenzó a Reinar”. Documento para la Historia de la Instrucción Primaria 1840-1920, DIBAM, Santiago de Chile, pp. 180-183.

Matte, Claudio (1890). "La Calidad de la Escuela y la Pobreza son Causas que Deben Considerarse que Afectan la Asistencia de los Niños a la Escuela”. En: Monsalve, Mario (1998) “...I y el Silencio Comenzó a Reinar". Documento para la Historia de la Instrucción Primaria 18401920, DIBAM, Santiago de Chile, pp. 189-190.

Monsalve, Mario (1998). “...I y el Silencio Comenzó a Reinar”. Documento para la Historia de la Instrucción Primaria 1840-1920, DIBAM, Santiago de Chile. 
Núñez, Iván (1986). Gremios de Magisterio. Setenta Años de Historia, PIIE, Santiago, 1986.

Núñez, Iván (2007). "La Profesión Docente: Saberes e identidades en su historia". Pensamiento Educativo. Vol. 41, 2, pp. 149-165.

Núñez, José (1890). "Conceptualización y Misión de la Escuela Moderna, Según el Inspector Jeneral de Instrucción Primaria, Expuesta en el Congreso Nacional Pedagógico". En: Monsalve, Mario (1998). “...I y el Silencio Comenzó a Reinar”. Documento para la Historia de la Instrucción Primaria 1840-1920, DIBAM, Santiago de Chile, pp. 184-188.

Palacios, Nicolás (1904). [1987]. La Raza Chilena: Libro Escrito por un Chileno para los Chilenos, Ediciones Colchagua, Santiago de Chile.

Recabarren, Luis Emilio (1910). "Ricos y Pobres". En: Recabarren, Luis Emilio (1971) El Pensamiento de Luis Emilio Recabarren, Tomo I, Editorial Camino de Victoria, Santiago de Chile, pp. 163-205.

Revista Escuelas Católicas (1902). "La Instrucción Obligatoria”. En: Monsalve, Mario (1998) “...I y el Silencio Comenzó a Reinar". Documento para la Historia de la Instrucción Primaria 1840-1920, DIBAM, Santiago de Chile, pp. 195-197

Salas, Darío (1917). [1967] El Problema Nacional, Editorial Universitaria, Santiago de Chile.

Salas, Manuel (1905) "Pertinencia entre la Instrucción Popular y las Condiciones Socioeconómicas". En: Monsalve, Mario (1998) “...I y el Silencio Comenzó a Reinar”. Documento para la Historia de la Instrucción Primaria 1840-1920, DIBAM, Santiago de Chile, p. 160.

Torrealba (1919). "La Instrucción en Beneficio de los Sectores Populares". En: Monsalve, Mario (1998). “...I y el Silencio Comenzó a Reinar”. Documento para la Historia de la Instrucción Primaria 1840-1920, DIBAM, Santiago de Chile, pp. 163-167.

Varios autores (1890). "Propuestas Formuladas para Hacer Obligatoria la Instrucción Primaria en el Primer Congreso Nacional Pedagógico”. En: Monsalve, Mario (1998) “...I y el Silencio Comenzó a Reinar”. Documento para la Historia de la Instrucción Primaria 1840-1920, DIBAM, Santiago de Chile, pp. 191-194.

Venegas, Alejandro (1910). [1998]. Sinceridad, Chile Íntimo en 1910, Ediciones CESOC, Santiago de Chile. 
